DOCTRINA

\title{
La autorización de utilización de una obra ajena en la Ley de Propiedad Intelectual chilena
}

\author{
The authorization of the use of a protectable works by a third party \\ in the Chilean Intellectual Property Law
}

\author{
Alfredo Sierra Herrero \\ Universidad de los Andes, Chile
}

\author{
Manuel Bernet Páez iD \\ Universidad de los Andes, Chile
}

\begin{abstract}
RESUMEN El propósito de este artículo es examinar cómo la Ley de Propiedad Intelectual regula la autorización como un medio para que el autor permita a un tercero explotar una obra suya. En primer lugar, analizaremos si su otorgamiento debe ser expreso o tácito. En segundo lugar, pretendemos determinar cuál es el contenido mínimo que debe revestir esta autorización. Ambas cuestiones son relevantes desde un prisma práctico, puesto que la Corte Suprema en recientes sentencias ha manifestado posiciones ambivalentes acerca de la forma que debe revestir la autorización consentida por el titular de los derechos de autor y cuáles serían sus elementos esenciales. En esta investigación proponemos que la Ley de Propiedad Intelectual solo contempla la autorización en términos expresos, la cual debe cumplir, al menos, con el contenido prescrito en su artículo 20 , inciso segundo.
\end{abstract}

PALABRAS CLAVE Derecho de autor, licencia de uso, derechos de explotación.

ABSTRACT The purpose of this article is to examine how the Chilean Intellectual Property Law regulates the authorization as a mean by which the author allows a third party to exploit his or her work. To accomplish said purpose, we review the manner in which it should be granted, that is, whether it must be explicit or if implied authorizations are also valid. Then, we focus on specifying what the minimum content that this authorization should fulfill is. Both issues are entirely relevant from a practical perspective, since there is ambivalence in recent Chilean Supreme Court decisions about the manner in which the authorization must be granted by the copyright holder and, also, concerning its essential elements. In this article, we propose that the Chilean Intellectual Property 
Law only allows for explicit authorizations, which must comply, at least, with the content prescribed in article 20 , subsection 2 therein.

KEYWORDS Copyright Law, licensing, copyright owner's rights.

\section{Introducción}

Las creaciones protegidas por la Ley de Propiedad Intelectual (Ley 17.336) tienen como origen la persona natural o física, ente capaz de ejecutar el proceso creativo. ${ }^{1}$ De este modo, la persona humana es la que adquiere todos los derechos morales y patrimoniales sobre su creación u obra (artículo 1). Se dispone así que el autor es el titular originario de la obra, mientras que será titular secundario aquel que adquiere los derechos sobre la obra del autor a cualquier título (artículo 7).

Se puede concluir que, inicialmente, todos los derechos de explotación de una obra se radican en su titular originario, el autor. Por tal razón, el tercero ajeno que desea utilizar dicha obra creada por otro deberá acreditar un título para ello. Esto, ya sea porque se le han transferido todos o algunos de los derechos de explotación sobre la misma, o bien porque el autor le ha concedido una autorización o permiso para su uso - lo que se denomina comúnmente como licencia- y, en tal caso, el creador retendrá los derechos sobre la obra en su patrimonio (Walker Echenique, 2014: 160).

El propósito de este estudio es examinar la autorización como el medio a través del cual un tercero puede explotar una obra ajena. Con miras a este objetivo, en primer lugar, revisaremos su forma de otorgamiento, esto es, si debe ser expresa, o si procede que se conceda en términos tácitos. ${ }^{2}$ En segundo término, buscaremos precisar cuál es el contenido mínimo de dicha autorización, y cuál es la sanción aplicable en el evento de que dicho contenido no esté regulado por las partes de un contrato. La cuestión planteada resulta relevante, puesto que la Corte Suprema en recientes

1. Lo expuesto es reconocido por nuestro legislador en el artículo 5 letras a) y b) de la Ley de Propiedad Intelectual, cuando al referirse a la obra individual y a la obra en colaboración, respectivamente, se indica que deben ser producidas por personas naturales. En la doctrina española, por todos: Saiz García (2000: 75).

2. Sobre las manifestaciones de voluntad, su clasificación más relevante es entre expresa y tácita. Así, Corral Talciani (2018: 529) indica que «la manifestación expresa es aquélla en que la voluntad se explicita mediante el instrumento de comunicación humana que es el lenguaje. La manifestación tácita, en cambio, es aquélla en que la voluntad se comunica, no por medio del lenguaje, sino a través de gestos o conductas corporales. [...] La manifestación expresa, la realizada a través de lenguaje, puede ser verbal, escrita o gestual. Es verbal si se utiliza el lenguaje oral; es escrita si la voluntad de una o ambas partes se expresa mediante la escritura en formato papel o digital. También debe considerarse una forma de manifestación expresa aquélla que se manifiesta a través del lenguaje gestual, como es la lengua de señas que utiliza la comunidad sorda (cfr. artículo 26, Ley 20.422)». 
sentencias ha manifestado una posición ambivalente, al exigir en algunas ocasiones una autorización expresa y en otras una licencia de carácter tácito.

Desde ya podemos adelantar que, a nuestro parecer, la Ley de Propiedad Intelectual sólo contempla como institución la autorización expresa, todo ello en atención al tenor literal de la Ley, a su historia fidedigna y a su interpretación sistemática. Asimismo, dicha autorización corresponde que sea concedida, al menos, cumpliendo con los requisitos mínimos dispuestos en el artículo 20, inciso segundo de la Ley de Propiedad Intelectual, según argumentaremos en los apartados siguientes.

\section{La vacilante posición de la Corte Suprema sobre la autorización del uso de una obra ajena}

A pesar de que la Ley 17.336 es de antigua data, pues su fecha de publicación es del 2 de octubre de 1970, nuestra Corte Suprema no había tenido la oportunidad de pronunciarse con detalle sobre los alcances de la autorización en materia de derecho de autor. Dicha autorización está reglamentada en los artículos 19 y 20 de la Ley. Es así como el artículo 19, inciso primero establece como regla general lo siguiente:

Nadie podrá utilizar públicamente una obra del dominio privado sin haber obtenido la autorización expresa del titular del derecho de autor.

La Corte Suprema, en los asuntos que debió conocer, sólo se limitó a reproducir el texto de la norma, no poder extraer de sus sentencias una postura específica sobre ese asunto. ${ }^{3}$ Sin embargo, es en la sentencia del 22 de marzo de 2016 donde es posible encontrar un primer pronunciamiento explícito sobre esta cuestión, tal como veremos a continuación.

\section{El caso Productora Dublin: La admisión de la autorización tácita}

Los hechos que motivaron este litigio consistieron en la utilización por parte de la productora de espectáculos Dublin Entertainment Inc. del repertorio musical de los artistas José Feliciano, Jerry Rivera, Pablo Milanés, Air Supply y Marco Antonio Solís sin autorización expresa de la Sociedad Chilena de Derecho de Autor (SCD), quien representa en Chile a tales intérpretes. Lo relevante de este caso es que la utilización de dichas creaciones tuvo lugar en conciertos de los mismos músicos.

El tribunal de primera instancia rechazó parcialmente la demanda, al considerar, entre otras razones, que la mayoría de los artistas mencionados son titulares en una parte de los derechos de ejecución de sus propias obras — por ejemplo, Pablo Milanés

3. Son ilustrativas de lo mencionado las siguientes sentencias de la Corte Suprema: sentencia del 24 de diciembre de 2008, rol 3.313-2007, y sentencia del 12 de noviembre de 2012, rol 8.440-2012. 
ostentaba el $50 \%$ de los derechos sobre sus obras-, por lo que su participación en tales eventos suponía una autorización contractual suficiente. ${ }^{4}$ La Corte de Apelaciones de Santiago confirmó la sentencia de primer grado, y en su voto de mayoría sostuvo que la presencia del titular de los derechos de autor comporta una autorización implícita en los términos de la Ley, criterio no compartido en el voto de minoría, que sostenía que la autorización de la utilización de una obra ajena debe ser expresa. ${ }^{5}$ En contra de esta última sentencia, la SCD interpuso un recurso de casación en el fondo, al sostener una incorrecta aplicación del artículo 19 de la Ley, puesto que la Corte de Apelaciones habría admitido que la autorización del uso de una obra ajena podía ser implícita, lo cual, a su juicio, repugnaba con el mandato del legislador que prescribe que la autorización debe ser expresa, lo cual no se satisface con la sola presencia del titular del repertorio en el espectáculo.

La Corte Suprema rechazó este recurso de casación en el fondo. En cuanto a los motivos esgrimidos en el voto de mayoría, sostuvo que, efectivamente, Dublin no obtuvo la autorización exigida por la Ley. Empero, señaló que la ejecución de las obras protegidas por sus autores tuvo lugar en recitales que ellos mismos intervinieron, debiendo entonces morigerarse el rigor interpretativo de la recurrente. Así, en lo que nos interesa, a fin de denegar el recurso, la Corte Suprema admitió la autorización tácita en esta materia al expresar:

Decimotercero: Que siendo un antecedente no controvertido y asumido por el demandante la ejecución pública del repertorio de los mismos artistas que realizaron conciertos, no parece justa la pretensión de la Sociedad Chilena de Derecho de Autor, pues en efecto, la sola presencia del creador de las obras importa una autorización, al menos tácita, a que se ejecute públicamente su obra en los conciertos en que participa, ya que concurre con su voluntad a que se difunda ante un público que es además su seguidor, y es bajo este prisma funcional con que también debe analizarse la masificación de la obra, pues ella no lo fue ante una generalidad indeterminada, sino más bien, frente a un grupo cautivo y en un recinto cerrado, a los que ingresaron pagando un determinado valor, convergiendo las acciones en un único propósito de promoción del mismo artista, siendo el beneficiado por este conjunto de actos, pues, contra lo que pudiera pensarse, el productor del espectáculo, percibió como ganancia el pago del ingreso al concierto y cada artista una contraprestación -usualmente dichos espectáculos no son gratuitos-; de lo anterior y siendo el titular de la obra el beneficiado, cómo podrían estimarse infringidas las disposiciones que, precisamente, buscan resguardar y proteger sus creaciones, de esta forma. ${ }^{6}$

Como puede apreciarse, la Corte Suprema reconoció en esta sentencia que un ter-

4. Sentencia del 24 Juzgado Civil de Santiago, 24 de junio de 2011, rol C-7094-2013.

5. Sentencia de la Corte de Apelaciones de Santiago, 30 de enero de 2015, rol 9.796-2014.

6. Sentencia de la Corte Suprema, 22 de marzo de 2016, rol 3.798-2015. 
cero distinto del autor puede utilizar una obra ajena, para lo cual bastaría la autorización tácita del titular, recordando que los artistas en la especie sólo eran propietarios de parte de sus derechos, circunstancia que fue considerada en el voto de minoría para acoger el recurso. ${ }^{7}$ Con todo, conviene subrayar que la Corte, en un supuesto fáctico análogo, modificó esta posición inicial dos años después, en su sentencia del 15 de mayo de 2018, en orden a entender que la autorización que debe otorgar el titular de los derechos de explotación a un tercero debe ser expresa. A continuación, analizamos esta sentencia.

\section{El caso Productora Transitorlab: El reconocimiento a la autorización expresa}

En este pleito, la recurrente, Productora de Eventos Transitorlab Limitada, interpuso un recurso de casación en el fondo en contra de la sentencia dictada por la Corte de Apelaciones de San Miguel, en cuya virtud se le condenó al pago de indemnización de perjuicios y a una multa a beneficio fiscal. ${ }^{8}$

En particular, en este recurso se imputaba por Transitorlab la incorrecta aplicación de diversas normas de la Ley 17.336, y en lo que nos interesa, de los artículos 17 y 18 de la Ley. En este punto, se indicaba por la recurrente que no debía obtener una autorización de la SCD (la demandante) respecto de la ejecución pública de obras de su repertorio en los recitales de los grupos Incubus y Pixies, puesto que precisamente las obras musicales referidas fueron ejecutadas por esas mismas agrupaciones, quienes a su vez eran sus autores. En palabras de esta recurrente, se señalaba:

Se desprende que al ejecutar el propio autor su obra resulta evidente que está otorgando de manera expresa la autorización para difundirla en el recital que él mismo está presentando al público. ${ }^{9}$

De esta suerte, la Corte Suprema, en el considerando 8 de su sentencia, determinó que la cuestión esencial en la resolución del recurso consistía en verificar si, conforme a la Ley 17.366, esta autorización esgrimida por la recurrente -que este tribunal calificaba como tácita- era acorde a las disposiciones legales. Luego, para motivar el

7. Es así que, en el voto de minoría, el abogado integrante Rodrigo Correa razona: «Este disidente estima que para la utilización pública de una obra es necesaria la autorización de todos los comuneros en los derechos de autor respectivos, la que puede obtenerse directamente de cada uno de ellos o de sus representantes, o de la entidad de gestión colectiva que corresponda. Esto es consecuencia de que dicha autorización es el vehículo que la Ley de Propiedad Intelectual ofrece para que todos los titulares del derecho de autor, muchas veces residentes en distintas jurisdicciones, puedan efectivamente beneficiarse de la explotación comercial de la obra. De lo contrario, el derecho de autor de quienes no han prestado su autorización queda desamparado».

8. Sentencia de la Corte de Apelaciones de San Miguel, 20 de julio de 2016, rol 791-2016.

9. Sentencia de la Corte Suprema, 15 de mayo de 2018, rol 55.082-2016, primer visto. 
rechazo del recurso, la Corte, en el voto de mayoría, se explayó, específicamente, en la cuestión de la autorización tácita en los siguientes términos:

Décimo: [...] En cuanto al carácter de la autorización que deben dar el titular o el conjunto de titulares del derecho de autor, ya sea por sí mismos o a través de la entidad de gestión colectiva correspondiente, esa autorización debe ser expresa. Así se desprende, sin la menor duda, del artículo 18 de la ley conforme a la cual sólo el titular del derecho de autor o quienes estuvieren expresamente autorizados tendrán el derecho de utilizar la obra en alguna de las formas que la ley señala. Del mismo modo, el artículo 19 reitera que «nadie podrá utilizar públicamente una obra del dominio privado sin haber obtenido autorización expresa del titular del derecho de autor» (lo que cabe referir a los titulares del mismo en el caso de obras musicales creadas en colaboración, pues en tal caso la facultad de autorizar corresponde al conjunto de sus coautores, según el mencionado artículo 23). Ese carácter expreso de la autorización resulta corroborado por el contenido que debe tener y que prolijamente señala el artículo 20, inciso segundo, del texto normativo en estudio, al exigir que contenga una precisión de los derechos concedidos a la persona autorizada; el plazo de duración; la remuneración y su forma de pago; el número mínimo o máximo de espectáculos o ejemplares autorizados y el territorio de aplicación y todas las demás cláusulas limitativas que el titular del derecho de autor imponga. Lo anterior se encuentra en sintonía con el principio doctrinal de independencia de los derechos económicos, que en nuestra legislación se encuentra consagrado expresamente en el inciso final del artículo 20, que dispone: «A la persona autorizada no le serán reconocidos derechos mayores que aquéllos que figuren en la autorización, salvo los inherentes a la misma según su naturaleza». De tal forma, no cabe sino concluir que la normativa exige una autorización explícita, descartando el uso de permisos tácitos. Aunque en los actos privados se admite, como principio, la voluntad tácita, tanto la doctrina como la jurisprudencia la rechazan como forma de manifestación cuando por norma legal o pacto contractual se exige la voluntad expresa, como en el caso en estudio. En otras palabras, en materia de derecho de autor, la autorización para el uso o explotación de una obra protegida debe ser explícita o directa, no pudiendo ser deducida de cierto comportamiento del autor o titular del derecho, sino que debe, necesariamente, existir un acto que de forma manifiesta e inequívoca autorice a un tercero a utilizarla de una manera particular. ${ }^{10}$

Como se advierte, en esta sentencia se establece que la autorización que concede el titular de una obra para que sea utilizada por otro debe ser expresa, y debe tener

10. Sentencia de la Corte Suprema, 15 de mayo de 2018, rol 55.082-2016, considerando 10. Se debe apuntar que en el voto de minoría, el ministro Ricardo Blanco reitera su opinión, ya expresada en el caso Dublin, en cuanto a que la presencia del creador de las obras en un espectáculo en que además interviene importa una autorización a que se ejecute públicamente su obra en los conciertos que participa, ya que concurre con su voluntad a que se difunda ante un su público seguidor. 
un contenido mínimo, que es aquel dispuesto en el artículo 20, inciso segundo de la Ley. De ahí que se debe descartar toda autorización tácita, como puede ser el hecho de deducir algún tipo de permiso por cierto comportamiento del autor, como lo es, según indica la sentencia, la propia ejecución del creador de su repertorio musical en un recital. Una vez expuesta esta divergencia de criterios por parte del máximo tribunal, nos corresponde formular nuestra tesis acerca de cuál es la posición más ajustada a la Ley.

\section{Primera tesis: La Ley 17.336 solo admite la autorización expresa}

De acuerdo a lo que hemos revisado, es posible apreciar por parte de la Corte Suprema dos posturas diametralmente opuestas en torno al artículo 19 de la Ley 17.336. Es así como en el caso Dublin, la Corte esgrime que la autorización que otorga el titular de los derechos de autor puede ser tácita, mientras que en el caso Transitorlab sostiene lo opuesto, al exigir que dicha autorización sea manifestada en términos expresos. A nuestro parecer, esta última posición es la correcta, conforme a los argumentos que pasaremos a revisar a continuación.

\section{El tenor literal de la Ley 17.336 no recoge la autorización tácita}

En cuanto al tenor literal de la Ley, el artículo 19 de la Ley 17.336 prescribe en su inciso primero que «nadie podrá utilizar públicamente una obra del dominio privado sin haber obtenido la autorización expresa del titular del derecho de autor». Lo mismo se reitera en el artículo 18, inciso primero, al decir: «Sólo el titular del derecho de autor o quienes estuvieren expresamente autorizados por él, tendrán derecho a utilizar la obra en alguna de las siguientes formas».

En relación a lo anterior, cabe destacar que el concepto de autorización de uso de una obra ajena se encuentra específicamente definido por el legislador; de ahí que, conforme al artículo 20 del Código Civil, se deba atender a dicho sentido. Es así que el artículo 20, inciso primero de la Ley 17.336 dispone que «se entiende por autorización el permiso otorgado por el titular del derecho de autor, en cualquier forma contractual, para utilizar la obra de alguno de los modos y por alguno de los medios que esta Ley establece». Y acto seguido, en su inciso segundo, determina cómo debe ser dicha autorización: «La autorización deberá precisar los derechos concedidos a la persona autorizada, señalando el plazo de duración, la remuneración y su forma de pago, el número mínimo o máximo de espectáculos o ejemplares autorizados o si son ilimitados, el territorio de aplicación y todas las demás cláusulas limitativas que el titular del derecho de autor imponga. La remuneración que se acuerde no podrá ser inferior, en caso alguno, al porcentaje que señale el Reglamento».

De las normas transcritas es posible colegir que: i) la autorización que concede el 
autor a un tercero debe ser expresa, y ii) que dicha cualidad se cumple exclusivamente bajo los parámetros impuestos en el artículo 20, inciso segundo de la Ley 17.336.

En otras palabras, no basta con que el autor autorice de manera patente - ya sea oralmente o por escrito- a un tercero a usar su obra, sino que tal permiso se tiene que manifestar cumpliendo con todos y cada uno de los requisitos impuestos por el artículo 20, inciso segundo de la Ley 17.336, debido a que tal norma impone qué debe comprenderse por autorización expresa. Luego, si esas exigencias obligatorias no son obedecidas, dicho tercero no se encontrará autorizado, y con ello, le será aplicable lo establecido en el inciso segundo del artículo 19 de la Ley 17.336, que dice: «La infracción de lo dispuesto en este artículo hará incurrir al o los responsables en las sanciones civiles y penales correspondientes».

A modo de resumen, se puede afirmar que, del tenor literal de la Ley 17.336, se prescribe que la autorización que otorga el autor - como titular originario- a un tercero para utilizar su obra debe ser expresa, destacando que tal carácter no puede ser obviado por las partes en atención al carácter protector de las normas sobre derecho de autor. ${ }^{11}$

\section{La historia fidedigna de la Ley 17.336 ratifica que la autorización debe ser expresa}

Como hemos indicado, el artículo 19 de la Ley 17.336 determina que la autorización que el autor concede a un tercero para que utilice su obra debe tener el carácter de expresa. De este modo, resulta relevador examinar cuál es la historia fidedigna de su establecimiento, y con ello verificar nuestra primera tesis.

El primer antecedente del artículo 19 precitado se encuentra en el Mensaje Presidencial del Proyecto de Ley, del 30 de diciembre de 1968, que posteriormente se convirtió en la Ley 17.336. En el mensaje se contemplaban los artículos 19 y 20 relacionados a esta materia, cuyo tenor era el siguiente:

Artículo 19: Las diversas formas del ejercicio del derecho patrimonial son independientes entre sí. La utilización de uno de ellos no afecta a los demás, salvo pacto en contrario. El autor retiene todos los derechos que no autoriza expresamente.

Artículo 20: Nadie podrá presentar en público obra del dominio privado sin haber obtenido previamente la autorización del titular del derecho de autor, bajo pena de incurrir en las sanciones civiles y penales establecidas en la Ley. ${ }^{12}$

11. En la doctrina francesa se destaca el carácter imperativo de las normas protectoras al autor, las cuales están impregnadas de un fuerte formalismo. Sobre esto, véase Lucas, Lucas y Lucas-Schloetter (2012: 568). En la doctrina española, se sitúa al autor como la parte débil en la contratación en materia de propiedad intelectual, y por ello las normas de ley están orientadas a su protección, tanto en sus intereses patrimoniales como morales. Sobre lo dicho, véase Evangelio Llorca (2006: 68-69); Rams Albesa (2010: 115).

12. «Historia de la Ley 17.336», Biblioteca del Congreso Nacional, p. 11, disponible en http://bit. ly/2HiOzNG. 
Con posterioridad, en el primer trámite constitucional, se modificó el tenor y numeración de las normas examinadas, de forma que los artículos 19 y 20 pasaron a ser los artículos 18 y 19, con su redacción quedando en los siguientes términos:

Artículo 18: Las diversas formas del ejercicio del derecho patrimonial son independientes entre sí. La utilización de uno de ellos no afecta a los demás. El autor retiene todos los derechos cuyos ejercicios no autoriza expresamente.

Artículo 19: Nadie podrá utilizar públicamente una obra del dominio privado sin haber obtenido la autorización del titular del derecho de autor. ${ }^{13}$

Luego, en el segundo trámite constitucional, en particular en el primer informe de la Comisión de Constitución, Legislación y Justicia del Senado, del 20 de marzo de 1970, es posible ubicar la actual redacción del artículo 19 de la Ley 17.336, como también de su artículo 20, que define qué es autorización y qué requisitos debe contemplar la misma. Es así como, junto con suprimir, por innecesario, el artículo $18,{ }^{14}$ se manifestaron como razones tenidas a la vista para reformular el proyecto de ley en trámite, las siguientes:

Se agregó al artículo 19, que sienta el principio básico de que nadie puede utilizar públicamente una obra del dominio privado sin previa autorización del titular del derecho de autor, un inciso que establece la sanción por la infracción correspondiente. ${ }^{15}$

Acto seguido, en lo que dice relación con la redacción definitiva del artículo 19 de la Ley 17.336 en este primer informe de la Comisión de Constitución, Legislación y Justicia del Senado, se resolvió lo siguiente:

Artículo 19: Ha intercalado a continuación de la palabra «autorización», la palabra «expresa». Ha agregado como inciso segundo, nuevo, el siguiente: «La infracción de lo dispuesto en este artículo hará incurrir al o los responsables en las sanciones civiles y penales correspondientes». ${ }^{16}$

De la historia fidedigna del artículo 19 de la Ley 17.336 consta inequívocamente que: i) inicialmente, en el proyecto de ley no se contemplaba en dicho artículo

13. «Historia de la Ley 17.336», p. 41.

14. Se debe mencionar que el artículo 18 fue suprimido debido a que se prefirió indicar las formas en que se puede utilizar una obra, sea directamente por el titular del derecho de autor, sea por quienes estuviesen autorizados por él. De este modo, resulta ilustrador reproducir su inciso primero, que en esa etapa del proyecto destaca nuevamente el carácter de expresa de la autorización, al decir: «Artículo 18: El titular del derecho de autor o quienes estuvieren expresamente autorizados por él, podrán utilizar la obra en alguna de las siguientes formas $[\ldots] »$.

15. «Historia de la Ley 17.336», p. 121.

16. «Historia de la Ley $17.336 »$, p. 137. 
que la autorización fuese expresa, ni cuáles requisitos debía cumplir la misma; ii) sin embargo, el carácter de expresa de la autorización sí se incluía en otras normas relacionadas, como era el antiguo artículo 18; iii) por lo que con el devenir del iter legislativo, de manera concluyente, se mantuvo dicha cualidad en la autorización, y se reforzó aún más la protección al autor, puesto que tal autorización expresa debía tener un contenido esencial, que es el dispuesto en el artículo 20, inciso segundo de la Ley 17.336.

En síntesis, no se podría sostener que la Ley 17.336 considera lícita la autorización tácita dada por el autor a favor de un tercero para que utilice su obra. En este punto, si siguiera tal interpretación, no solo sería contraria al tenor literal de la Ley, sino particularmente a su historia fidedigna, en la cual queda patente que la intención del legislador fue disponer que esta autorización debía tener el carácter de expresa, y que dicha exigencia exclusivamente se cumpliría con el contenido mínimo dispuesto al efecto en el artículo 20, inciso segundo de la Ley 17.336.

\section{La interpretación sistemática de la Ley 17.336 no admite la autorización tácita}

Nuestra opinión, acerca de que la Ley 17.336 solo reconoce la autorización expresa, encuentra suficientes fundamentos en el tenor literal e historia fidedigna de su establecimiento. Sin embargo, cabe examinar si de manera armónica entre los distintos artículos de la Ley 17.336 se obtiene un similar resultado.

Sobre lo dicho, el artículo 19 de la Ley 17.336 se encuentra ubicado en el capítulo 5, párrafo 1, titulado «Del derecho patrimonial en general». Este párrafo se inicia con el artículo 17 de la Ley, que describe de qué manera el autor puede explotar su obra, ya sea utilizándola personalmente, transfiriendo sus derechos sobre ella o autorizando su utilización por terceros.

A continuación, con el fin de acotar respecto de qué facultades patrimoniales precisas se detentan sobre una creación, el artículo 18 de la Ley, en su inciso primero, prescribe: «Sólo el titular del derecho de autor o quienes estuvieren expresamente autorizados por él, tendrán el derecho de utilizar la obra en alguna de las siguientes formas». A continuación, el artículo 19, inciso primero reitera que la autorización del titular del derecho de autor debe ser expresa.

Acto seguido, el artículo 20, en su inciso primero de la Ley define lo que debe entenderse por autorización, y en su inciso segundo detalla cuál es su contenido mínimo. Entre otras menciones, se refiere a la necesidad de determinar qué derechos se le conceden a la persona autorizada, la vigencia de la autorización y su remuneración. Luego, en su inciso final establece que:

A la persona autorizada no le serán reconocidos derechos mayores que aquellos que figuren en la autorización, salvo los inherentes a la misma según su naturaleza. 
Respecto de este último inciso, resulta revelador que el legislador haya empleado el verbo «figurar», puesto que ello da cuenta de que la autorización necesariamente debe ser expresa y, por ello, bajo ninguna perspectiva podrá ser tácita. Ello es así, puesto que por «figurar», según una de las acepciones del Diccionario de la RAE, se debe comprender: «4. intr. Dicho de una cosa: Aparecer o constar en algún lugar. Al pie del documento figura la firma del autor». Luego, por «constar», este mismo diccionario señala: «1. intr. Dicho de una cosa: Ser cierta o manifiesta». Finalmente, por «manifiesta», este mismo texto dispone: «1. adj. Descubierto, patente, claro».

De esta forma, según lo dispone el inciso final del artículo 20 de la Ley, en la autorización que se concede por el titular del derecho de autor a favor de un tercero, deben figurar los derechos concedidos, esto es, debe constar o aparecer de manera patente tal exigencia, requisito que evidentemente repugna con la idea de una autorización tácita.

Finalmente, los artículos 21 y 22 de la Ley 17.336, nuevamente, se refieren a la autorización, y es destacable que el artículo 21, inciso final de la Ley reenvía a los artículos anteriores, y el artículo 22 contempla una norma específica tratándose de las autorizaciones de las obras literarias o musicales.

De esta manera, se puede apreciar que el legislador ha reglamentado de forma sistemática la autorización para el uso de una obra ajena. En un principio (artículo 19) determina que es una facultad inherente al titular de una obra. Luego señala que los derechos de explotación patrimonial sólo podrán ser utilizados por aquel que ha sido autorizado expresamente, tal como se dispone en el artículo 19 de la Ley 17.336.

Adicionalmente, para evitar dudas acerca de qué se entiende por autorización, el artículo 20, inciso primero define dicha expresión, y en sus incisos segundo y tercero se reitera el carácter de expresa de la autorización, puesto que la misma debe contemplar un contenido mínimo, y en cuanto a los derechos concedidos al tercero autorizado se dispone que no le serán reconocidos más que aquéllos que figuren en la autorización, esto es, que consten de manera patente en ella, salvo los inherentes a la misma según su naturaleza.

\section{La doctrina no reconoce la autorización tácita cuando la Ley requiere que sea expresa}

Como cierre, cabe examinar qué ha dicho la doctrina respecto de la autorización tácita, ya sea en el ámbito del derecho común, como también en el sector específico de la propiedad intelectual. Como tendremos ocasión de revisar, también en esta fuente del derecho se confirma nuestra interpretación acerca de que la Ley 17.336 no reconoce la autorización tácita para utilizar una obra ajena.

En sede de derecho común, la doctrina ha estudiado la voluntad como uno de los elementos de la existencia de un acto jurídico. De este modo, se reconoce que la 
voluntad puede manifestarse de manera expresa o tácita, ambas con similar valor jurídico. Ahora bien, los autores están contestes en que no es procedente la voluntad tácita cuando la Ley requiere que la misma sea expresa, como ordena el artículo 19 de la Ley 17.336.

Sobre esto, Pescio (1948a: 45) afirma: «La ejecución de hechos que supongan voluntad es inoperante cuando la ley exige, como en la novación, una declaración categórica (artículo 1.636), o cuando el acto es solemne». Del mismo modo, León Hurtado (1963: 50) - quien en nuestro país es el autor que ha estudiado la voluntad con un particular detalle - sostiene: «La ley exige a veces que la voluntad se exteriorice de un modo expreso; la voluntad tácita no sería suficiente para generar el acto jurídico o producir el efecto deseado por su autor». En similar sentido, Domínguez Águila (1977: 41) concuerda con los demás autores, al señalar que: «En ciertos negocios, la ley exige una manifestación expresa, y no es posible deducir esa manifestación de hechos que la supongan implícitamente. Así sucede en el artículo 1.465». Finalmente, Guzmán Brito (1992: 218) razona en similares términos, al decir: «La ley suele excluir la manifestación tácita de dos maneras: bien diciendo esto directamente, como en el caso del artículo 1.211 CC [...]; bien exigiendo de algún modo que la manifestación sea expresa, con lo cual elimina indirectamente la tácita».

Por tanto, no cabe duda de que en el derecho común, cuando la Ley requiere que la voluntad debe ser manifestada de forma expresa, no es jurídicamente admisible la voluntad tácita para perfeccionar el acto jurídico en particular. Para que se generen los efectos inherentes al mismo, como lo sería en este caso con la autorización de la utilización de una obra ajena, se exige que la autorización sea expresa.

Asimismo, el criterio civilista es acogido por la doctrina del derecho de la propiedad intelectual, la cual desestima la autorización tácita en esta materia. Así, a modo de ejemplo, Herrera Sierpe (1999: 86) expresa sobre el artículo 19 de la Ley lo siguiente: «De la lectura del artículo 19, es posible concluir que la autorización no puede ser verbal, ni puede ser tácita o presunta». Por su parte, Elisa Walker, al referirse a las formalidades que se deben cumplir para autorizar a terceros el uso de una obra protegida, señala:

Esta autorización es definida como «el permiso otorgado por el titular del derecho de autor, en cualquier forma contractual, para utilizar la obra de alguno de los modos y por alguno de los medios que esta ley establece». La Ley exige que dicha autorización se realice en forma expresa, descartando de tal forma el uso de autorizaciones tácitas. Junto con ser expresa, la autorización debe contener una serie de elementos. Debe precisar los derechos concedidos a la persona autorizada, indicar un plazo de duración, una remuneración y a su forma de pago, establecer el número mínimo o máximo de espectáculos o ejemplares autorizados o si son ilimitados, el territorio de aplicación, junto con todas las cláusulas limitativas que el titular del derecho de autor imponga (Walker Echenique, 2014: 185-186). 
En síntesis, de la revisión de la doctrina nacional, ya sea la propia del derecho común o la de la propiedad intelectual, es posible concluir que ambas están contestes en afirmar que, en los casos en que la Ley requiere que un acto jurídico se perfeccione por voluntad expresa, no es posible en modo alguno admitir la voluntad tácita. En lo que nos interesa, no es jurídicamente aceptable, entonces, interpretar que la Ley 17.336 permita la autorización tácita en el uso de una obra ajena, lo cual es, además, contrario al tenor literal de los artículos 19 y 20 de la Ley 17.336.

\section{Una correcta lectura a los casos Dublin y Transitorlab}

Finalmente, cabe resolver si en los dos asuntos examinados, el titular de los derechos de autor otorgó una autorización expresa con relación a la utilización de sus obras. Sobre ello, ambos litigios tienen como denominador común la circunstancia de que las creaciones implicadas fueron ejecutadas públicamente por sus autores —en este caso músicos-, y por dicha razón las productoras demandadas negaban el pago adicional de una licencia a la SCD en los términos del artículo 21, inciso primero de la Ley 17.336 .

Acerca de lo dicho, un primer alcance a efectuar es que entre la productora u organizadora de eventos y los artistas se celebra un contrato de prestaciones de servicios, que implica que la primera debe pagar a los segundos una contraprestación de dinero a cambio de la cual estos últimos deben ejecutar públicamente creaciones musicales a su favor, que pueden o no ser de su autoría. Por lo tanto, el objeto de dicho negocio jurídico es exclusivamente la autorización de la explotación pública de los derechos conexos que ostenta el artista sobre sus ejecuciones, de conformidad con lo prescrito en el artículo 65 de la Ley 17.336 (Altés Tárrega, 2017: 1.343-1.344).

Acto seguido, una segunda observación es que este contrato de prestación de servicios en modo alguno afecta a los derechos de autor que tienen sus titulares - ya sea originarios o secundarios- con respecto de las obras musicales ejecutadas por los artistas, tal como dispone el artículo 65, inciso segundo de la Ley 17.336. De ahí que, tratándose de los cantautores, sujetos que reúnen los roles de autores y de artistas, podrán detentar la titularidad de los derechos de autor sobre sus obras, y además disponer de la titularidad de los derechos conexos sobre las interpretaciones de las mismas producciones musicales.

Una vez asentadas estas premisas conceptuales, es posible volver sobre los casos analizados. En este sentido, la cuestión a despejar es si la mera celebración de un contrato de ejecución pública de creaciones musicales entre los artistas - que también eran sus autores- con las productoras constituye adicionalmente una autorización del titular del derecho de autor para permitir que tales las obras sean usadas en los referidos conciertos. En este punto, debemos recordar que en el caso Dublin, la Corte Suprema admitió que la presencia de los músicos en los eventos contratados era una 
autorización tácita, mientras que en el caso Transitorlab sostuvo que la ejecución pública del repertorio propio por los músicos no configuraba una autorización conforme ordena el artículo 20, inciso primero de la Ley 17.336.

A nuestro parecer, la respuesta a tal interrogante debe ser similar a la resuelta por la Corte Suprema en el caso Transitorlab. Ello, por dos razones. La primera, debido a que la Corte Suprema confunde en el caso Dublin las calidades de autor y de artista, sujetos que a su vez detentan derechos sobre objetos distintos. En este sentido, el autor es el creador de una obra, y por ello goza de los derechos patrimoniales y morales dispuestos en la Ley sobre tal producción, mientras que el artista es quien interpreta una obra propia o ajena y se le conceden derechos conexos sobre dicha interpretación. De este modo, el artista no tendrá la calificación de autor, ni sus interpretaciones serán estimadas como creaciones u obras (Sánchez Aristi, 2017: 1.536).

A partir de lo dicho, en el caso de la ejecución de obras musicales en un concierto, se deberá contar con al menos las autorizaciones pertinentes dadas, por una parte, por el titular de los derechos de autor sobre las creaciones musicales ejecutadas, y por la otra, por el titular de los derechos conexos sobre la interpretación de dichas obras. Ahora bien, en el caso Dublin quedó asentado como hecho que los artistas ejecutantes no eran los titulares exclusivos de los derechos de autor, puesto que solo le pertenecían el 50\% de los mismos; de ahí que, aunque se considerase que su intervención en tales eventos constituida una autorización de uso conforme prescribe el artículo 20 de la Ley 17.336, este supuesto permiso adolecía de ineficacia, puesto que se requería para su perfeccionamiento el consentimiento del otro comunero de tales derechos de autor.

El segundo argumento para justificar nuestra posición se refiere al pago de la remuneración por la autorización dada por el titular de los derechos de autor. En este punto, debemos recordar que el contrato de prestación de servicios entre la productora y los artistas tiene por propósito remunerar a estos últimos por la ejecución pública de ciertas obras musicales, propias o ajenas. Luego, dicho negocio jurídico, tal como prescribe el artículo 65 de la Ley, en modo alguno puede menoscabar la protección que se dispensa a los autores. Por lo tanto, si el artículo 20, inciso primero de la Ley requiere que los titulares de los derechos de autor autoricen expresamente la utilización de sus creaciones, tal mandato imperativo no puede ser desconocido por las partes al convenir sobre derechos conexos. Adicionalmente, tal autorización debe ser remunerada según dispone el artículo 20, inciso segundo de la Ley, suma que debe ser pagada al titular de los derechos de autor si sus creaciones son ejecutadas públicamente, tal como prescribe el artículo 21 de la Ley. ${ }^{17}$

Finalmente, cabe añadir que al exigir la Ley la presencia de una autorización expresa por parte del titular de los derechos de autor para utilizar una obra ajena, será

17. Esta regla es reiterada en el artículo 64 de la Ley 17.336. 
de cargo del tercero probar la existencia de dicho permiso, sin que sea suficiente para ello la sola celebración de un contrato de prestación de servicios cuyo objeto son naturalmente los derechos conexos del artista sobre su interpretación, a menos que en tal convenio se añada una autorización respectiva por el titular de los derechos de autor en los términos del artículo 20 de la Ley 17.336, lo cual además está en consonancia con lo prescrito en el artículo 21, inciso segundo del mismo cuerpo normativo.

\section{El contenido de la autorización expresa dada por el titular de los derechos de autor}

Asentada la premisa de que la autorización que debe otorgar el titular de los derechos de autor a un tercero debe ser expresa, corresponde determinar si la misma debe tener un contenido mínimo. A este respecto, bien se puede estimar que es necesario cumplir con aquel contenido que prescribe el artículo 20, inciso segundo de la Ley, o bien, se puede pensar que esa descripción es solo orientadora para las partes, de modo que su omisión no acarrea sanción alguna. Para apreciar la relevancia de esta cuestión, examinaremos una sentencia dictada por la Corte Suprema el 18 de enero de 2018, que nos permitirá adentrarnos en este debate.

En este litigio, el recurrente Octavio Fuentes interpuso un recurso de casación en el fondo, en contra de la sentencia dictada por la Corte de Apelaciones de Santiago, la cual denegó su pretensión indemnizatoria deducida en contra de la Empresa Nacional de Minería (Enami) ${ }^{18}$ En este sentido, son hechos relevantes de esta causa la circunstancia de que el demandante prestó sus servicios de soporte informático a favor de Enami entre los años 2007 a 2012, y que también en esa época elaboró un programa computacional denominado Sistema de Recepción de Minerales (SIREM). De este modo, luego de extinguida esta relación contractual, el demandante presentó una acción por infracción a sus derechos de propiedad intelectual, puesto que -en lo que nos interesa- Enami habría hecho un uso no autorizado de SIREM en el mismo periodo antes mencionado.

La Corte de Apelaciones de Santiago, aun reconociendo que el contrato de prestación de servicios no contenía una cláusula que permitiera ceder la titularidad de SIREM a favor de Enami, consideró que presumiblemente el demandante autorizó su uso a favor de dicho empresa, puesto que en virtud de la relación contractual que los unía, fue el mismo demandante quien ejecutó la instalación y aplicación del software en dependencias de Enami, y por la cual recibió un honorario. Tales actuaciones, para esta Corte, vinculaban al demandante, y por ello era procedente la aplicación a esta litis de la doctrina de los actos propios. De esta manera, se rechazó la apelación al no demostrarse que Enami hubiese utilizado el software sin autorización de su titular.

18. Sentencia de la Corte de Apelaciones de Santiago, 1 de junio de 2016, rol 8.615-2015. 
En el recurso de casación en el fondo interpuesto en contra de la sentencia revisada, el recurrente denunció una infracción a los artículos 18 y 20 de la Ley 17.336, puesto que en su concepto no habría habido una autorización expresa para que Enami utilizara el software, y que el contrato de prestación de servicios invocado por la Corte de Apelaciones no contenía cláusulas de derechos de autor que cumplieran con las exigencias impuestas en el artículo 20, inciso segundo de la Ley.

La Corte Suprema rechazó el recurso en una sentencia dividida. Así, en el voto de mayoría inicialmente ratificó su posición en cuanto a que la autorización que debe dar el titular del derecho de autor ha de ser expresa, no admitiéndose, por tanto, que sea tácita ni presunta. Sin embargo, sostuvo, a continuación, que el recurrente sí prestó su autorización expresa en la utilización del software por parte de Enami, razonando que

el demandante exteriorizó o reveló su voluntad a través de una declaración escrita - calidad que tienen las cartas o cotizaciones que remitió a la demandada- ofreciendo o poniendo a su disposición de aquélla el programa computacional ya referido, que incluso personalmente instaló, aplicó, implementó, por lo que se le pagaron los respectivos honorarios, se debe concluir que los jueces del fondo no infringieron lo que disponen los artículos 1, 18 y 20 de la Ley 17.336, al desestimar la demanda de indemnización de perjuicios, pues, precisamente, como lo señalaron, no se acreditó el supuesto fáctico fundamental, esto es, la falta de autorización expresa del autor de la obra intelectual de que se trata para su utilización en las instalaciones de la demandada. ${ }^{19}$

Por su parte, en el voto de minoría redactado por el ministro Ricardo Blanco se argumentó en un sentido contrario. Sostuvo así que en esta materia la Ley exige una autorización formal o documental. Por ello se descarta el uso de permisos tácitos, de modo que no es posible deducir dicha voluntad de cierto comportamiento del titular del derecho. Esto, a su juicio, queda corroborado por el contenido que debe tener la autorización, según dispone el artículo 20, inciso segundo de la Ley. De esta suerte, en lo que dice relación al recurso, el ministro afirmó que:

el fallo impugnado incurrió en un error de derecho al estimar que el demandante había manifestado su voluntad en un sentido de que la demandada instalara y usara el programa computacional respecto de la cual tiene derechos en calidad de autor, y concluir que había autorizado expresamente el uso del referido programa, a partir del hecho de haber aceptado en calidad de contratista ejecutar servicios computacionales vinculados con el programa. ${ }^{20}$

19. Sentencia de la Corte Suprema, rol 44.948-2016, 18 de enero de 2018, considerando 8 . 20. Sentencia de la Corte Suprema, rol 44.948-2016, considerando 4, voto de minoría. 
De esta manera, en esta sentencia ambos votos comparten la opinión de que la autorización en cuestión corresponde que sea expresa, esto es, debe ser manifestada a través del lenguaje hablado, escrito o gestual. Sin embargo, difieren en cómo la autorización tiene que manifestarse. Por un lado, el voto de mayoría admite que la misma pueda expresarse a través de actos unilaterales del titular, y sin cumplir al parecer con el contenido descrito en el artículo 20, inciso segundo de la Ley. Por otro, el voto de minoría concluye que el contenido mínimo del artículo 20, inciso segundo de la Ley es imperativo para las partes. A continuación, analizaremos cuál de éstas es la postura que tendría que ser la correcta.

\section{Segunda tesis: Solo es válida como autorización expresa la otorgada en los términos del artículo 20, inciso segundo de la Ley}

A nuestro parecer, conforme con los argumentos que se expondrán, la tesis más adecuada a esta cuestión es considerar que solo es válida como autorización expresa aquélla que es otorgada de acuerdo con el contenido mínimo dispuesto en el artículo 20 de la Ley, y en particular, su inciso segundo, norma que es de orden público, y por ello no disponible para las partes.

A fin de fundamentar esta segunda tesis, revisaremos la historia fidedigna del precepto precitado, qué nos dice al respecto el derecho comparado y, por último, interpretaremos armónicamente la Ley 17.336.

\section{La historia de la Ley 17.336 confirma la imperatividad de su artículo 20}

En cuanto a la génesis de la regla en examen, se debe apuntar que ésta no se encontraba en el mensaje presidencial que dio origen a la Ley 17.336. De hecho, la misma se incorpora en el primer informe de la Comisión de Constitución, Legislación y Justicia del Senado, que indicó lo siguiente:

El artículo 21 del proyecto de la Cámara, que especificaba los derechos que adquiere, en virtud de una autorización concedida por el titular del derecho de autor, la persona en favor de la cual se otorgaba dicha autorización, fue sustituido por otro que señala qué se entiende por autorización, esto es, el permiso otorgado, en cualquier forma contractual, para utilizar la obra de alguno de los modos y por alguno de los medios que la ley establece. La nueva disposición señala también el contenido esencial de las estipulaciones respectivas. ${ }^{21}$

De este modo, en dicha etapa del proceso legislativo, el artículo 20 fue redactado en los siguientes términos (similares al actualmente vigente):

21. «Historia de la Ley 17.336», p. 122. 
Artículo 20: Se entiende por autorización el permiso otorgado por el titular del derecho de autor, en cualquier forma contractual, para utilizar la obra de alguno de los modos y por alguno de los medios que esta ley establece.

La autorización deberá precisar los derechos concedidos a la persona autorizada, señalando el plazo de duración, la remuneración y su forma de pago, el número mínimo o máximo de espectáculos o ejemplares autorizados o si son ilimitados, el territorio de aplicación y todas las demás cláusulas limitativas que el titular del derecho de autor imponga.

A la persona autorizada no le serán reconocidos derechos mayores que aquéllos que figuren en la autorización, salvo los inherentes a la misma según su naturaleza. ${ }^{22}$

Luego, fue en el segundo informe de la Comisión de Constitución, Legislación y Justicia del Senado donde se perfiló la redacción definitiva del texto, al añadirse en el inciso segundo la siguiente frase:

La remuneración que se acuerde no podrá ser inferior, en caso alguno, al porcentaje que señale el Reglamento. ${ }^{23}$

A partir de lo reseñado, es posible deducir como primera observación que, según la historia de la Ley, se disponía que la autorización debía otorgarse: i) contractualmente - lo que impide considerar como autorización el acto unilateral de una de las partes-, y ii) que tal autorización debía tener un contenido mínimo esencial. Así, respecto de esta última afirmación, se debe recordar que los elementos esenciales de un acto jurídico - como lo es la autorización-son aquellas cosas sin las cuales el acto no produce efecto alguno, o degenera en otro distinto, como prescribe el artículo 1.444 del Código Civil.

Como un segundo apunte, cabe mencionar la notable influencia que tuvo en la redacción de la norma el autor brasilero Henry Jessen, cuya obra Derechos intelectuales de los autores, artistas, productores y otros titulares fue traducida por el abogado asesor del Ministerio de Educación, Luis Grez Zuloaga, quien participó de manera activa en la tramitación de la Ley 17.336. ${ }^{24}$

22. «Historia de la Ley 17.336», p. 137.

23. «Historia de la Ley 17.336», p. 217. No se contienen mayores referencias en la historia de la Ley respecto de los motivos de esta agregación. Así, solo se señala que: «El artículo 20 reglamenta las convenciones que puedan celebrarse entre el autor y los utilizadores de su obra, englobadas bajo la denominación de «autorizaciones». A este respecto, se aprobó una indicación del señor Fuentealba conforme a la cual la remuneración que se pacte no podrá ser inferior a la que señale el Reglamento» (p. 209).

24. La influencia de la obra de Jessen en la tramitación de la Ley 17.336 se aprecia en numerosos pasajes de su historia, como se observa en el siguiente comentario del senador Patricio Aylwin: «Tengo a la mano, precisamente, algunos párrafos del libro Derechos intelectuales, de Henry Jessen, que la comisión consultó a menudo, por ser una de las mejores publicaciones de habla castellana sobre la materia», (p. 262). 
Esto resulta evidente, puesto que los incisos segundo y tercero del artículo 20 de la Ley fueron redactados de manera casi idéntica a como lo hace Jessen, quien, a propósito de la licencia o autorización del autor o cesionario dada en cualquier forma contractual, afirma:

La autorización del autor deberá ser precisa en sus términos, indicándose en ella cuáles son los derechos que se conceden al usuario, el plazo de duración, la remuneración y su forma de pago, el número mínimo o máximo de espectáculos o ejemplares autorizados, o si son ilimitados, el territorio de aplicación y todas las demás cláusulas limitativas que el autor quiera imponer. Al licenciado no le serán reconocidos derechos mayores que aquéllos que figuren en la autorización, salvo si por ser habituales en el país y, por consiguiente, de aplicación lógica y necesaria, las partes no lo mencionen por considerarlos obvios (Jessen, 1970: 101).

Como se puede apreciar, las similitudes entre este pasaje extractado y el artículo 20 de la Ley son patentes, puesto que destaca que la autorización debe ser precisa en sus términos, esto es, expresa, y que debe tener un contenido mínimo para que produzca sus efectos.

A modo de resumen, podemos afirmar que en la historia de la Ley se pretendió delimitar la manera en que el autor debe otorgar la autorización para que otro utilice su obra. No se trata por tanto de un acto carente de deslindes, sino que, por el contrario, su fuente tiene que ser un contrato, cualquiera que éste sea, y en el mismo es necesario que se detalle un conjunto de elementos que se consideran como esenciales. Éstos son: i) los derechos concedidos al autorizado; ii) el plazo de vigencia de la autorización; iii) la remuneración y forma de pago; iv) el número mínimo o máximo de espectáculos o ejemplares o sin ilimitados, y v) el ámbito territorial de la licencia.

\section{La sanción en el derecho francés a las cesiones irregulares de derechos}

Nos parece importante dar cuenta del estado de la cuestión en el derecho francés contemporáneo a la dictación de nuestra Ley, ya que evidentemente a esa fecha tal ordenamiento desplegaba una enorme influencia en los demás sistemas jurídicos pertenecientes al derecho continental.

En ese tiempo en Francia regía en esta materia la Ley sobre Propiedad Artística y Literaria, Ley 57-298, del 11 de marzo de 1957. Según menciona Denoix de Saint Marc, el legislador era receloso de que los autores contrataran con empresarios que tienen una mejor posición para negociar $y$, por tanto, de imponer sus condiciones a esta parte débil. Por esta razón, se establecieron un conjunto de reglas para limitar el alcance de la cesión de los derechos de autor consentidas por sus titulares, principalmente con miras a hacerlos reflexionar sobre las consecuencias jurídicas de sus actos. En tal sentido, se sostuvo que estas disposiciones tenían el carácter de imperativas, lo que se 
justificaba por la preocupación del legislador de evitar que a los autores se les privara indebidamente de sus derechos (Denoix de Saint Marc, 1999: 179).

De este modo, en lo que nos interesa, el artículo 31, párrafo tercero, de la Ley de 1957 (actual artículo L131-3 del Código de Propiedad Intelectual francés) prescribe una regla muy similar al artículo 20, inciso segundo de Ley 17.336. En tal norma se indica lo siguiente:

La cesión de los derechos del autor estará subordinada a la condición de que cada uno de los derechos cedidos sea objeto de una mención por separado en el contrato de cesión y que el ámbito de explotación de los derechos cedidos quede delimitado en cuanto a su alcance y su destino, así como en cuanto al lugar y a la duración. ${ }^{25}$

Conforme a estos términos, si una cesión de derecho de autor omite alguna de las menciones obligatorias descritas en la norma, la doctrina sostiene que tal contrato sería ineficaz, puesto que carecería de objeto. Y es que la norma prescribe que la cesión está subordinada al cumplimiento de los requisitos descritos, de modo que si éstos no se cumplen, se considera que la cesión sería ineficaz. Ahora bien, la discusión se circunscribe a si la sanción de ineficacia sería la nulidad absoluta o relativa. Para algunos autores, debería declararse la nulidad absoluta, puesto que faltaría un elemento de la esencia del contrato. Para otro sector, con miras a proteger de mejor forma el interés del sujeto tutelado, sostienen que la sanción debería ser la nulidad relativa, pudiendo ser ratificada la cesión irregular. ${ }^{26}$

En síntesis, en el derecho francés que estaba vigente a la fecha de dictación de la Ley 17.336, era un requisito de la esencia de una cesión de derecho de autor que se cumplieran las especificaciones mínimas descritas en el artículo 31 de la Ley de 1957. Sobre esta base, no resulta válida la autorización si en el contrato consta sólo una mención genérica a alguna de estas exigencias (Denoix de Saint Marc 1999: 179; Lucas, Lucas-Schloetter y Bernault 2017: 624; Pollaud-Dulian 2014: 945). A este respecto resulta ilustrativo el criterio de la Corte de Casación, que consideró nula una cesión en que se estipulaba que el autor transfería todos sus derechos sobre una obra, toda vez que con ello se infringía la regla de especificidad de los derechos cedidos por el titular a un tercero. ${ }^{27}$

25. Una versión traducida al castellano del Código de Propiedad Intelectual francés se encuentra en http://bit.ly/2IZI9Wq. Por otro lado, se debe advertir que en el derecho francés la distinción entre cesión y licencia - que sí se contiene en la Ley 17.336 (artículos 20 y 73) - no es relevante, puesto que ambos actos están sometidos a las mismas reglas. Sobre esto, véase Lucas, Lucas-Schloetter y Bernault (2017: 609) y Raimond (2009: 35).

26. Por todos: Lucas, Lucas-Schloetter y Bernault (2017: 625).

27. Cour de Cassation, chambre civile 1, 9 de octubre de 1991, disponible en http://bit.ly/2ZBt585. La disputa que resolvió esta sentencia se refería a una controversia sostenida entre una agencia de publicidad (Roberts and Partners) con su cliente (Joker). Así, ambas partes celebraron un contrato de encargo 


\section{Una interpretación armónica no tolera una autorización alejada del tenor expreso del artículo 20, inciso segundo de la Ley 17.336}

Como hemos revisado, tanto en la historia de la Ley como en el derecho francés se distingue el carácter tuitivo que despliega la legislación sobre la propiedad intelectual. Justamente es en el momento en que el titular de los derechos desea explotar su obra cuando se requiere una mayor tutela, por lo cual el artículo 20, inciso segundo de la Ley necesariamente cumple un papel de orden público y, por ello, imperativo para las partes.

Lo expresado es consistente con la historia fidedigna de la Ley. En ella, al referirse a la irrenunciablidad de los derechos patrimoniales contenida en el artículo 86 de la Ley $17.336,{ }^{28}$ se indica:

Una de las materias más importantes en que la Comisión innovó respecto del proyecto de la Cámara de Diputados es la relativa a la irrenunciabilidad de los derechos patrimoniales que la ley en proyecto otorga a los titulares de los derechos de autor y conexos. En el artículo 100 del proyecto primitivo, se establecía que «las normas de la presente ley son supletorias de la voluntad de las partes», lo que dejaba en la indefensión más absoluta a los autores frente a los empresarios y explotadores habituales del trabajo ajeno, y hacía enteramente inútil la iniciativa en estudio. Siguiendo la tendencia existente, que lleva a asimilar cada vez más al derecho laboral la legislación protectora de la creación intelectual, la Comisión sustituyó esa disposición por el artículo 86 y estatuyó la irrenunciabilidad de los derechos patrimoniales. En esta forma acogimos una sentida y justa aspiración de los autores. Por lo tanto, ninguna convención o contrato celebrado por los titulares del derecho de autor podrá establecer cláusulas que contengan beneficios inferiores a los determinados en la ley, y si así ocurriere, esas estipulaciones no tendrán valor alguno. ${ }^{29}$

Adicionalmente, tal como hemos indicado, no cabe desconocer el tenor expreso del artículo 20, inciso segundo de la Ley que, al referirse a los contenidos esenciales

de obra publicitaria, por la cual la agencia se comprometía a hacer creaciones publicitarias a favor de su mandante respecto de jugos de fruta, estipulándose en el mismo que se incluía la cesión de todos los derechos de explotación. Con posterioridad, la agencia de publicidad encargó un film llamado «La fruta desnuda», respecto de la cual su contratante Joker reclamó su titularidad, argumentando que había adquirido todos los derechos de explotación de las creaciones publicitarias producidas por la agencia Roberts and Partners. La Corte de Casación resolvió a favor de la agencia de publicidad, puesto que, a pesar de la estipulación pactada, su aplicación ilimitada en los hechos despoja de toda fuerza obligatoria al artículo 31, párrafo tercero, de la Ley de 1957.

28. El artículo 86 de la Ley 17.336 prescribe: «Son irrenunciables los derechos patrimoniales que esta Ley otorga a los titulares de los derechos de autor y conexos, especialmente los porcentajes a que se refieren los artículos 50, 61, 62 y 67».

29. «Historia de la Ley 17.336», p. 192. 
de la autorización, prescribe: «La autorización deberá precisar». Se trata, evidentemente, de una norma imperativa, puesto que ordena cómo debe llevarse a cabo este acto jurídico (Pescio, 1948b: 277). Como el legislador exige que el acto se ejecute de manera especial, no tienen la facultad de celebrar el mismo en otra forma a la dispuesta, ya que ello sería contrario al interés general (León, 1983: 29).

Por otro lado, cabe destacar que el carácter esencial de las menciones que debe contener la autorización - descritas en el artículo 20, inciso segundo de la Ley- se aprecia con toda nitidez al revisar las demás normas de la Ley 17.336. En este sentido, nuestro legislador no estableció ninguna regla de supletoriedad, en ausencia de la voluntad de las partes respecto del contenido de la autorización. A modo de contraste, la Ley española de propiedad intelectual, en su artículo 43, apartado segundo, al referirse a la transmisión entre vivos de los derechos de autor suple la voluntad de las partes de la siguiente forma:

2) La falta de mención del tiempo limita la transmisión a cinco años y la del ámbito territorial al país en el que se realice la cesión. Si no se expresan específicamente y de modo concreto las modalidades de explotación de la obra, la cesión quedará limitada a aquella que se deduzca necesariamente del propio contrato y sea indispensable para cumplir la finalidad del mismo.

Por lo tanto, si en el contrato nada se dice respecto de cuáles son los derechos concedidos al tercero (ya sea el derecho de reproducción o de distribución), o cuál será el ámbito temporal de la explotación (de duración definida o perpetua) o su alcance territorial aplicable a la autorización (Chile o todo el mundo), sólo cabe considerar que ésta será ineficaz. Este razonamiento se confirma con la regla de interpretación estricta del artículo 20, inciso final de la Ley, que dispone que, al menos, en la autorización deben figurar los derechos objeto de la misma, cuestión que en caso alguno puede ser integrada por el juez.

En resumen, tanto de la historia fidedigna de la Ley 17.336 como de lo expuesto en el derecho comparado, y adicionalmente, de una interpretación armónica del texto legal, es posible considerar que sólo será válida una autorización dada por el titular de los derechos de autor a un tercero cuando la misma cumpla de manera íntegra el contenido dispuesto en el artículo 20, inciso segundo de la Ley. De lo contrario, se considerará ineficaz. En esta línea, dado el carácter obligatorio de las menciones impuestas en dicha norma, corresponde concluir que su omisión acarrea, en principio, la nulidad por la falta de los requisitos que la Ley considera como esenciales del acto (Corral Talciani, 2018: 673). . $^{\circ}$

30. Para este autor, la hipótesis de un acto jurídico al que le faltan uno o más de sus requisitos esenciales se deben sancionar con su nulidad de pleno derecho, la que opera ipso iure. Esta idea se recoge en Corral Talciani (2018: 673-676). 
Sin embargo, a nuestro juicio, se podría considerar que la sanción aplicable en la especie sería la dispuesta en el artículo 19 de la Ley, inciso segundo de la Ley, que prescribe que, a falta de autorización concedida por el titular, al infractor se le hará responsable de las sanciones civiles y penales dispuestas en la Ley, todo ello en relación al artículo 10 del Código Civil, que prescribe que la Ley puede establecer un efecto distinto a la nulidad en caso de contravención (Claro Solar, 1939: 597). Así, el tercero que utiliza una obra ajena sin contar con una autorización en los términos del artículo 20, inciso segundo de la Ley, carece de una autorización expresa, tal como la requiere el artículo 19, inciso primero de la Ley, por lo que, acto seguido, debe ser considerado un infractor civil y penal, según indica el inciso segundo del precitado artículo.

\section{Conclusiones}

El propósito de este estudio fue examinar cómo la Ley de Propiedad Intelectual reglamenta la autorización como un medio a través del cual el autor permite a un tercero explotar una obra suya. En este sentido, dimos cuenta de que la Corte Suprema ha mostrado una posición vacilante acerca de la forma en que debe concederse la autorización por el titular de los derechos de autor a los terceros, así como el contenido mínimo que la misma debe revestir. Tal disparidad de criterios en la jurisprudencia obliga a esclarecer ambas cuestiones debatidas.

La primera tesis de nuestro estudio consiste en afirmar que la Ley de Propiedad Intelectual solo admite la autorización expresa del titular de los derechos de autor para que un tercero pueda utilizarla. Tal proposición se asienta en el tenor literal de la Ley 17.336, en la historia fidedigna de su establecimiento, en una interpretación sistemática de sus normas, y finalmente, en la opinión común de los autores.

La segunda tesis de nuestra investigación considera que solo es válida como autorización expresa dada por el titular de derechos de autor a un tercero, aquélla que cumple con los requisitos mínimos impuestos en el artículo 20, inciso segundo de la Ley de Propiedad Intelectual. Luego, la omisión de tales menciones obligatorias trae como consecuencia que al tercero no autorizado se le hará responsable de las sanciones civiles y penales, conforme lo dispone el artículo 19, inciso segundo de la Ley.

\section{Agradecimientos}

La redacción de este artículo ha contado con la ayuda del Fondo Nacional de Ciencia y Tecnología de la República de Chile, en el marco del Proyecto Fondecyt Regular núm. 1170894, titulado «Propiedad intelectual y derecho del trabajo: Régimen jurídico de las creaciones realizadas por el trabajador», en el cual los autores tienen la calidad de investigador responsable y coinvestigador, respectivamente. 


\section{Referencias}

Altés TÁrrega, Juan Antonio (2017). «Comentario artículo 110». En Felipe Palau Ramírez y Guillermo Palao Moreno (directores), Comentarios a la Ley de Propiedad Intelectual. Valencia: Tirant lo Blanch.

Claro Solar, Luis (1939). Explicaciones de derecho civil chileno y comparado. Tomo 12. Santiago: Nascimento.

Corral Talciani, Hernán (2018). Curso de derecho civil: Parte General. Santiago: Thomson Reuters.

Denoix De SAINT MARC, Stéphanie (1999). Le contrat de commande en droit dauteur français. París: Litec.

Dominguez Águila, Ramón (1977). Teoría general del negocio jurídico. Santiago: Jurídica de Chile.

Evangelio Llorca, Raquel (2006). El encargo de obra intelectual. Madrid: Dykinson.

GuZmán Brito, Alejandro (1992). «Contribución a la crítica del dogma de la voluntad como fuente de efectos jurídicos: La voluntad específica en los actos jurídicos de derecho patrimonial privado». En Enrique Barros Bourie (coordinador), Contratos. Santiago: Jurídica de Chile.

Herrera Sierpe, Dina (1999). Propiedad intelectual: Derechos de autor. Ley 17.336 y sus modificaciones. Santiago: Jurídica de Chile.

Jessen, Henry (1970). Derechos intelectuales de los autores, artistas, productos de fonogramas y otros titulares. Trad. de Luis Grez Zuloaga. Santiago: Jurídica de Chile.

León Hurtado, Avelino (1963). La voluntad y la capacidad en los actos jurídicos. Santiago: Jurídica de Chile.

-. (1983). El objeto en los actos jurídicos. Santiago: Jurídica de Chile.

LuCAS, André, Agnès Lucas-Schloetter y Bernault, Carine (2017). Traité de la propieté littérarie et artistique. París: Lexis Nexis.

Lucas, André, Henri-Jacques Lucas y Agnès Lucas-Schloetter (2012). Traité de la propieté littérarie et artistique. París: Lexis Nexis.

Pescio, Victorio (1948a). Manual de derecho civil: Teoría general de los actos jurídicos y teoría general de la prueba. Santiago: Jurídica de Chile.

-. (1948b). Manual de derecho civil: Título preliminar del Código Civil. Santiago: Jurídica de Chile.

Pollaud-Dulian, Frédéric (2014). Propriété intellectualle: Le droit d’auteur. París: Economica.

Saiz García, Concepción (200o). Objeto y sujeto del derecho de autor. Valencia: Tirant lo Blanch.

SÁnChez ARISTI, Rafael (2017). "Comentario derechos de los artistas intérpretes o ejecutantes». En Rodrigo Bercovitz Rodríguez-Cano (coordinador), Comentarios a la Ley de Propiedad Intelectual. Madrid: Tecnos. 
RAImond, Sébastian (2009). La qualification du contract d'auteur. París: Litec.

Rams AlbeSA, Joaquín J. (2010). Siete estudios sobre el derecho de autor y la propiedad intelectual. Madrid: Reus.

WAlKer Echenique, Elisa (2014). Manual de propiedad intelectual. Santiago: Legal Publishing.

\section{Sobre los autores}

Alfredo Sierra Herrero es abogado. Doctor en Derecho por la Universidad de Santiago de Compostela, España. Profesor de Derecho Laboral de la Universidad de los Andes, Chile. Su correo electrónico es asierra@uandes.cl. (D) http://orcid. org/0000-0002-1302-0081.

Manuel Antonio Bernet Páez es abogado. Doctor en Derecho por la Universidad de los Andes. Profesor de Derecho Comercial de la Universidad de los Andes. Su correo electrónico es mbernet@uandes.cl. (D) http://orcid.org/oooo-0oo2-8668-9528. 


\title{
REVISTA CHILENA DE DERECHO Y TECNOLOGÍA
}

La Revista de Chilena de Derecho y Tecnología es una publicación académica semestral del Centro de Estudios en Derecho Informático de la Facultad de Derecho de la Universidad de Chile, que tiene por objeto difundir en la comunidad jurídica los elementos necesarios para analizar y comprender los alcances y efectos que el desarrollo tecnológico y cultural han producido en la sociedad, especialmente su impacto en la ciencia jurídica.

\author{
EDITOR GENERAL \\ Daniel Álvarez Valenzuela \\ (dalvarez@derecho.uchile.cl) \\ SITIO WEB \\ rchdt.uchile.cl \\ CORREO ELECTRÓNICO \\ rchdt@derecho.uchile.cl \\ LICENCIA DE ESTE ARTÍ́CULO \\ Creative Commons Atribución Compartir Igual 4.o Internacional
}

\begin{abstract}
La edición de textos, el diseño editorial
y la conversión a formatos electrónicos de este artículo

estuvieron a cargo de Tipográfica

(www.tipografica.cl).
\end{abstract}

